\title{
Effects of putative stressors in public aquaria on locomotor activity, metabolic rate and cortisol levels in the Mozambique tilapia Oreochromis mossambicus
}

\author{
H. LeOnG*, A. F. H. Ros*† And R. F. Oliveira* \\ *Unidade de Investigação em Eco-Etologia, Instituto Superior de Psicologia Aplicada, \\ Rua Jardim do Tabaco 34, 1149-041 Lisbon, Portugal and \$Instituto Gulbenkian de \\ Ciência, Rua da Quinta Grande 6, 2780-156 Oeiras, Portugal
}

(Received 10 April 2008, Accepted 5 February 2009)

\begin{abstract}
Mozambique tilapia Oreochromis mossambicus were housed individually during 7 days in a continuous flow-trough respirometry system and daily exposed to one of three treatments: (1) a series of knocks on the side of the aquarium, (2) a series of photo-flashes and (3) control group. Exposure to photo-flashes did not change locomotor activity but decreased both nighttime and daytime oxygen consumption throughout the experiment. Knocking induced a shortlived increase in locomotor activity and tended to increase oxygen consumption, but this latter effect was not significant. Night-time oxygen consumption was not affected by knocking exposure. Cortisol levels assayed from fish-holding water collected at the end of the experiment were significantly lower in subjects exposed to photo-flashes than in subjects exposed to knocks or controls. Males did not respond differently than females to the treatments in any of the measurements taken. In summary, the data reported here suggest that exposure to repetitive photo-flashes, but not knocking, suppressed normal energy metabolism and cortisol levels. These effects were present hours to a half day after exposure to the flashes. 2009 The Authors Journal compilation (C) 2009 The Fisheries Society of the British Isles
\end{abstract}

Key words: activity patterns; fish-holding water method; flash; noise; oxygen consumption; stress.

\section{INTRODUCTION}

Many regular events, such as reproduction or seasonal changes, challenge the individual's ability to maintain homeostasis. As a response to these challenges, an individual may activate a specific set of neural, neuroendocrine and neuroimmune mechanisms (Selye, 1936; McEwen, 1998). Often this response includes an acute increase in glucocorticoid levels, and the metabolic and behavioural effects of these steroids are usually effective for the animal to release itself from the stressor or to adapt to the stressor. In case the animal is not able to adapt

$\uparrow$ Author to whom correspondence should be addressed at present address: Department of Behavioural Ecology, University of Neuchâtel, Rue Emile-Argand II, 2009 Neuchâtel, Switzerland. Tel.: +41 32718 3004; fax: +41 32718 3001; email: afhros@gmail.com 
to the stressor, for example when the occurrence of the stressor is unpredictable, the resulting chronically increased glucocorticoid levels may lead to pathology (McEwen, 1998; McEwen \& Wingfield, 2003). Therefore, prevention of chronic stress by monitoring possible sources of stressors is of vital importance for the well-being of animals held in captivity.

Recent discoveries on pain mechanisms in fishes (Sneddon, 2002; Sneddon et al., 2003) and the increasing awareness that fishes are able to execute complex cognitive programmes (Bshary et al., 2002; Chandroo et al., 2004) have increased the attention made to issues of welfare in fishes (Braithwaite \& Huntingford, 2004). In public aquaria, visitors expect to see healthy and naturally behaving fishes. Many activities of the visitors, however, can potentially act as stressors for the fishes. Despite the potential role of visitors as a source of stressors for fishes in public aquaria, surprisingly little research has been carried out on their actual effects on fish behaviour and physiology.

Stressors have been defined as actions that result in impediment of normal behavioural activity and an increase in glucocorticoid levels (Oidtmann \& Hoffmann, 2001; Barton, 2002). In fishes for example, catch and release angling has been shown to impair locomotor activity, e.g. largemouth bass Micropterus salmoides (Lacépède) (Cooke et al., 2000), while confinement has been shown to result in a rise in the main teleost glucocorticoid cortisol (Vijayan et al., 1997; Arends et al., 1999; Haddy \& Pankhurst, 1999). Furthermore, changes in cortisol levels after exposure to a stressor have been shown to modulate energy metabolism and behavioural activity in fishes (Vijayan et al., 1997; Arends, 1999; Barton, 2002; Sunny et al., 2002).

The two main sources of putative stressors commonly present in public aquaria are sounds and visual stimuli. Sounds may increase cortisol levels as has been found for playback of white noise in the goldfish Carassius auratus (L.) (Smith et al., 2004a) and playback of intermittent noise (recorded from below a ship) but not Gaussian noise in perch Perca fluviatilis L., the common carp Cyprinus carpio L. and the gudgeon Gobio gobio (L.) (Wysocki et al., 2006). Visual stimuli may mask or mimic biologically relevant signals for fishes and thus hinder normal behavioural activity in these environments (Kratochvil \& Schwammer, 1997). Therefore, fluctuating noise and vibrations produced by visitors, such as knocking on aquaria walls and taking pictures with flashes, have been highlighted as putative stressors for fishes in the aquaria. In this study, the effects of such putative stressors were investigated.

As a study model, the cichlid fish Oreochromis mossambicus (Peters) was chosen since in this species metabolism and stress physiology has been well studied (Job, 1969; Kutty, 1972; van Ginneken et al., 1996, 1997; Vijayan et al., 1997; Ros et al., 2004, 2006). As putative stressors, either a series of knocks on the side of the aquarium or a series of photo-flashes were used. These treatments were compared with a treatment in which individuals were neither exposed to knocks nor to flashes. The aim of the experiment was to query both short-lived and long-lived consequences of these stimuli on activity and energy metabolism. Cortisol levels were measured at the end of the experiment using the non-invasive fish-holding water method. 


\section{MATERIALS AND METHODS}

\section{ANIMAL HANDLING}

Experimental fish were selected from a stock of individuals kept in the fish housing facilities of the Instituto Superior de Psicologia Aplicada (Lisbon, Portugal). In the stock tanks (750-800 1), fish were fed once every other day with commercial flakes for tropical fishes (Tropical Flake, Astra; http://astra-aquaria.de/index.php?id=17). During the experiment, fish were fed daily proportionally to their body mass $(4.5 \mathrm{~g}$ $\mathrm{kg}^{-0.8} \mathrm{day}^{-1}$ of pellet food; Ros et al., 2004). In the respirometry boxes, food was applied through a small opening in the lid of the respirometry box that was closed with a rubber stopper. Food was given at 0900 hours and $90 \mathrm{~min}$ after feeding the water flow was increased to wash out uneaten food that could contaminate the oxygen measurements.

Stock aquaria were equipped with a bottom filter of sand. In the respirometry system, water was continuously filtered over charcoal (Eheim; www.eheim.de) and passed a UV lamp. All water was gradually renewed and was continuously aerated (turnover time $c$. 1 week). The water temperature was kept at $26^{\circ} \mathrm{C}$, range $\pm 1^{\circ} \mathrm{C}$, and the photoperiod regime used was $12 \mathrm{~L}: 12 \mathrm{D}$.

\section{EXPERIMENTAL PROCEDURES}

In total, 54 fish were selected to be subjected to one of three experimental treatments: (1) 'knock' treatment, fish received a series of knocks daily on the side of the aquarium; (2) 'flash' treatment, fish received a series of photo-flashes daily and (3) control group, fish were neither subjected to knocks nor to flashes. These treatments were given in three trials, where each trial consisted of six fish in individual compartments that underwent the same treatment. Furthermore, the treatments of consecutive trials were alternated to correct for any order effect. Due to size constraints of the stock groups, eight juvenile fish were used in the experiment. These were later discarded from the analysis resulting in a final sample size of 46 individuals ('knock' group: six males and eight females; flash group: seven males and 10 females; control: nine males and six females).

On day 1 of each trial, six fish from the stock were caught and weighed $(M)$, and individually housed in 121 aquaria, visually isolated from other fish. Fish were kept in isolation for 7 days before the start of the experiment. This isolation prior to experimentation has been standard laboratory procedure to normalize the body condition of the experimental fish and to reduce carry-over effects of prior experience (Ros et al., 2004; Oliveira et al., 2005).

At day 8, fish were weighed and individually housed in 3.51 respirometry boxes (a description of the respirometry system is given, Ros et al., 2004). Neighbours were visually isolated by a black opaque division placed between boxes.

From day 9 until day 16 of each trial, animals were exposed to their assigned stimuli. In order to apply the knocking stimulus, a $150 \mathrm{~mm}$ iron bolt of $88 \mathrm{~g}$ with a rubber stop was hung on a hinge $200 \mathrm{~mm}$ above each aquarium. By operating a lever from behind a curtain, all hinges were quickly lowered and each bolt fell with the rubber stop on top of each aquarium, resulting in a simultaneous knock. Qualitative comparison of spectrograms confirmed that this resulted in a sound that was comparable to a human made knock on the aquarium with most energy in frequencies, $<500 \mathrm{~Hz}$. Oreochromis mossambicus produces courtship sounds that have most power in this range (Amorim et al., 2003). In each trial, two knocks (c. $2 \mathrm{~s}$ interval between knocks) were given every $3 \mathrm{~min}$ for $30 \mathrm{~min}$, which corresponds to 20 knocks in the period in which the stress was given.

Flashes were generated by means of a digital camera (Canon Power Shot G1; www.canon.com). Flashes were shot at different angles. This was done in order to prevent the fish from habituating. During the experience, 15 flashes were shot in each 3 min, which corresponded to 150 flashes in the period in which the stress was given. 
The stimulus intensity of flashes and knocks was chosen based on an estimation of the exposure to these stimuli of fishes in a public aquarium in Lisbon (Lisbon Oceanarium during the high season; I. Marques da Silva \& R. F. Oliveira, unpubl. data). The stimulus intensity value was doubled because the public aquarium has an active policy of not allowing the use of flashes to take pictures and visitors are instructed not to knock on aquaria walls. Research at the Aquarium House of the Tiergarten Schönbrunn, Vienna, Austria, has shown that such a policy approximately halves the amount of stimulation (Kratochvil \& Schwammer, 1997).

\section{CALORIMETRIC SYSTEM AND OXYGEN CONSUMPTION MEASUREMENTS}

Energy metabolism was measured using an open flow-through respirometry system (Cech, 1990), designed to record oxygen concentrations sampled from eight different respirometry boxes at constant intervals (Ros et al., 2004). Water was kept at a constant temperature of $26^{\circ} \mathrm{C}$ (range $\pm 1^{\circ} \mathrm{C}$ ), filtered over charcoal (Eheim filter) and oxygenated with an air stone. Each respirometry box was made from flat, optically clear 12 $\mathrm{mm}$ thick perspex (outside dimensions $154 \times 154 \times 262 \mathrm{~mm}$ ). Between boxes, a black partition was placed in order to visually isolate neighbouring fishes. A respirometry box containing no fish was used as a blank control to correct for possible background consumption of oxygen by micro-organisms living in the system.

Automated continuous-flow sampling allowed oxygen consumption of several respirometry boxes to be measured with a single sensor $\left(\mathrm{CellOx}{ }^{\circledR}\right.$ fitted with stirrer type R2 300 in a through flow cell type D201; WTW GmbH; www.wtw.com). The output of the oxygen meter (Oxi 197; WTW GmbH) was logged to a computer that allowed automated online acquisition of the data for later analysis.

The treatments were repeated four times per day. During the first three treatment sessions: from 1100 to 1200 hours, 1400 to 1500 hours and 1600 to 1700 hours, oxygen consumption and locomotor activity were measured. For fine scale measurements of oxygen consumption during the treatments, the valves of the respirometry system were programmed to sample water of two fish, simultaneously resulting in one recording of the treatment per fish per day. For these two fish, oxygen consumption measurements were started $0.5 \mathrm{~h}$ pre-exposure and continued $0.5 \mathrm{~h}$ during exposure to the experimental stimulation [according to their group assignment: flashes, knocks or none (control)]. To correct for possible effects of time of day on the oxygen consumption measurements, individuals were sampled during different sessions on subsequent days. During the last session, at 1800-1900 hours, the animals were exposed to their assigned stimuli but without measuring oxygen consumption and locomotor activity. During the dark phase (night-time), which started at 2100 hours and lasted until 0800 hours, the valves of the respirometry system were programmed to sample oxygen consumption of all animals.

Metabolic rates were calculated following Cech (1990). The commonly used allometric factor of 0.8 was used to correct oxygen consumption rates $(R)$ for $M\left(R M^{-0 \cdot 8} \mathrm{mmol}\right.$ $\mathrm{O}_{2} \mathrm{~h}^{-1} \mathrm{~kg}^{-0.8}$ ) (Job, 1969; Clarke \& Johnston, 1999; O. mossambicus: Ros et al., 2004). In order to assess the effect of the putative stressors, routine metabolic rates were calculated from measurements logged 15 min before and during exposing the animals to the stimuli and during the dark phase (night-time) when locomotor activity was zero (Ros et al., 2004). There was no immediate effect of stressor treatments on oxygen consumption. Therefore, to keep measurement periods comparable to the activity measurements, oxygen consumption was calculated over the last 15 min of the stimulus period.

\section{MEASUREMENT OF LOCOMOTOR ACTIVITY}

In order not to disturb the fish, observations and application of the treatment were carried out from behind a blind $c$. $500 \mathrm{~mm}$ in front of the respirometry boxes. Locomotor activity was recorded from the last $15 \mathrm{~min}$ of each experimental period (before 
and during applying the assigned stimuli) every second day. Under each respirometry box, a grid was drawn with one horizontal line over the length and three lines over the width of the respirometry box, resulting in eight equal partitions $\left(c .3800 \mathrm{~mm}^{2}\right.$ each). As a measure of locomotor activity, the number of times the tip of the snout of the observed individual passed one of the gridlines was recorded.

\section{CORTISOL MEASUREMENT}

As a non-invasive alternative to blood sampling from fish, cortisol was measured from fish-holding water (Scott et al., 2001; Hirschenhauser et al., 2002; methods adapted from Hirschenhauser et al., 2004). The sample procedure involved some handling, which is likely to be stressful for the fish (collecting of the water and catching of the fish). Therefore, in order not to interfere with the oxygen consumption measurements, fish-holding water was sampled at the last day of the trial.

On the day of fish-holding water collection, fish were not fed nor were the fish exposed to any of the treatments. At 1100 hours, 1.8 1 water was collected from the respirometry boxes. Immediately after collection, water was filtered through filter paper. Thereafter to trap the lipophilic phase, each sample was passed through a solid phase chromatography column (Merck LiChrolut RP-18, $500 \mathrm{mg}$; www.merck-chemicals.com) using a vacuum pump. These columns had previously been activated with $5 \mathrm{ml}$ of methanol followed by $5 \mathrm{ml}$ of distilled water. The columns were subsequently eluted with $2 \times$ $2 \mathrm{ml}$ of ethanol, and the solution with the eluted steroids was stored at $-20^{\circ} \mathrm{C}$ until further processing.

A relatively large part of steroids are excreted from circulation after being conjugated to sulphates or glucuronides. In order to measure total cortisol excretion, the extraction procedures of Scott \& Sorensen (1994) were followed with modifications described by Oliveira et al. (1996). This extraction procedure included three phases: (1) after evaporating the ethanol and adding $0.5 \mathrm{ml}$ of phosphate buffer, diethyl ether was used to extract the low polar (free) fraction from the buffer; (2) the sulphate-conjugated fraction was extracted after incubation with trifluoroacetic acid in ethyl acetate and (3) the glucuronide-conjugated fraction was extracted after enzymatic hydrolysis with glucuronidase. The resulting unbound steroid residues were pooled and dissolved in analysis buffer. A radioimmunoassay was carried out to quantify these residues using a polyclonal antibody (Fitzgerald Industries International, Inc.; www.fitzgerald-fii.com catalogue number $=20$-CR50), which has crossreactivity of $5 \cdot 7 \%$ for 11 -desoxycortisol, $3.3 \%$ for corticosterone and $<0.7 \%$ for cortisone. The sensitivity of the assay was $0.4 \mathrm{ng} \mathrm{ml}^{-1}$. All samples were processed in a single assay with an intra-assay coefficient of variance (c.v.) of $1 \cdot 3 \%$. Cortisol values are expressed as the total amount of cortisol contained in each sample corrected for $M$ and sampling volume (1 1$)$. Probably due to interference with dissolved organic matter in the circulation, some of the blank respirometry boxes had detectable cortisol immunoreactivity. Therefore, these 'zero' values were subtracted from the values measured in the fish-holding respirometry boxes to correct for background noise in the measurements.

\section{STATISTICAL TREATMENT}

All statistics were calculated using SPSS 14 package (SPSS Inc.; www.spss.com). Normality of data was tested by means of Kolgomorov-Smirnov tests. Only for the variables 'locomotor activity' and 'cortisol level', did the data significantly deviate from the normal distribution $(P<0 \cdot 05)$. Therefore, in order to carry out repeated measurements ANOVA, these data were transformed by $\log _{10}(x+1)$. Correlations were tested using the Spearman rank correlation. In the light of the relatively high $n$-value, this correlation test reaches the power of parametric tests (Pearson) but does make fewer assumptions on the type or order of the relationship between the variables tested. 
In order to optimize the analysis of general changes in the data due to treatment while minimizing loss of power (via the decrease of d.f.), data were pooled over three different intervals: 2 nd +3 rd day, 4 th +5 th day and 6 th +7 th day. The first day was excluded because fish show some changes in oxygen measurements during the first day that might be due to adapting to the new housing condition (Ros et al. 2004). Repeated measurement ANOVA were calculated with interval period as repeated factor $(n=3$, see above) and sex (male and female) and treatment group ('control', 'knock' and 'flash') as independent factors. Dependent variables tested in the ANOVA were: (1) metabolic rate and activity data measured before exposing the fish to their assigned stimuli; (2) metabolic rate and activity data representing the direct effect of the stimuli. These variables were calculated as the value measured during exposure to the assigned stimuli minus the value measured in the period before this exposure; (3) metabolic rate measured during the night-time phase and (4) cortisol measurements taken at the end of the experiment. Simple contrasts with the control group as a reference were applied for testing of treatment effects.

\section{ETHICAL CONSIDERATIONS}

In previous respirometry experiments, $O$. mossambicus did not show evident signs of distress (Ros et al., 2004, 2006). Furthermore, in those experiments, social behaviour of animals that were isolated in the respirometry boxes for several days did not seem to have been compromised (Ros et al., 2004, 2006; Oliveira et al., 2005). Therefore, the temporary confinement in the respirometry boxes was not considered stressful for O. mossambicus. After the trials, all fish were returned to their original stock tank. None of the fish died or showed evident signs of stress (inactivity or hyperactivity) after the experiment. The procedures used are in compliance with the regulations on animal experimentation in Portugal.

\section{RESULTS}

\section{TREATMENT EFFECTS ON ACTIVITY AND METABOLISM}

Daytime spontaneous locomotor activity (measured before exposure to the assigned stimuli) was highly variable between individuals [Fig. 1(a); mean \pm S.E. C.V. $=68 \pm 6 \%, n=46)$. Spontaneous locomotor activity was not significantly correlated with $M$ fish (Spearman rank correlation, $n=46$, all periods: $\left.r_{\mathrm{s}}<0 \cdot 16, P>0 \cdot 05\right]$. Treatment did not cause general changes in spontaneous locomotor activity [Fig. 1(a); ANOVA, d.f. $=1,42, P>0.05$; all interaction effects $P>0 \cdot 05]$ During the exposure to the assigned stimuli, a significant change was detected in activity depending on the type of stimulus applied [Fig. 1(b); ANOVA, treatment: d.f. $=1,42, P<0 \cdot 01]$, with knocks increasing the activity, while flashes had no significant effect (ANOVA simple contrasts: 'knock', $P<$ 0.05; 'flash', $P>0 \cdot 05$ )

Daytime routine metabolism (mean \pm S.E. C.V. $=11 \pm 2 \%, n=46$ ) did not differ significantly between the control and the knock groups but was significantly decreased in the flash group [Fig. 2(a); ANOVA, d.f. $=2,42$; effect treatment: $P<0.01$; simple contrasts: 'flash', $P<0.01$; 'knock', $P>0 \cdot 05$ ]. A similar trend was found for the lowest night-time routine metabolism (Fig. 3; ANOVA, d.f. $=2,42, P<0.05$; simple contrasts: 'flash', $P<0.01$; 'knock', $P>0.05)$. In contrast to activity, routine metabolism did not change significantly as a direct result of exposure to the assigned stimuli [Fig. 2(b); ANOVA, main effects: 

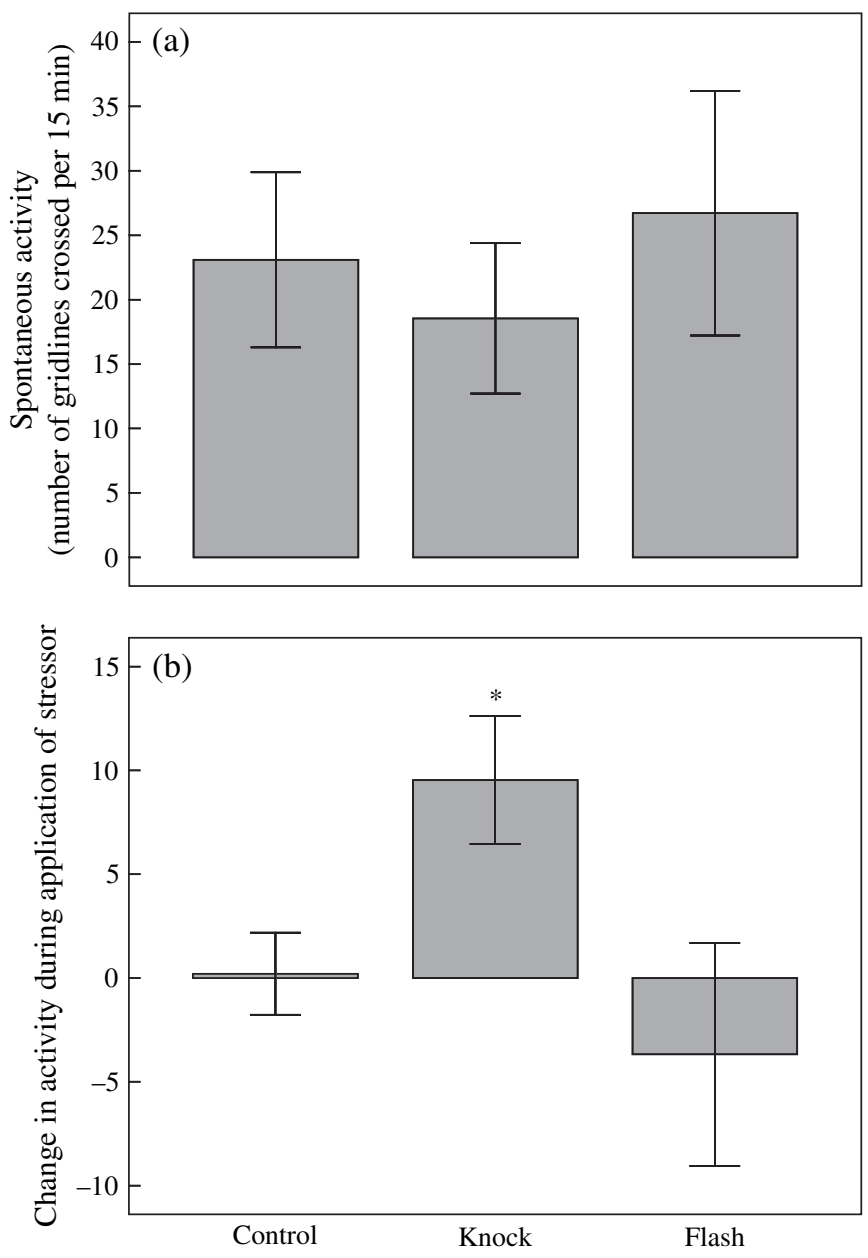

FIG. 1. The effect of 7 days of experimental treatment on Oreochromis mossambicus locomotor activity. The knock group was exposed to repetitive knocks against the wall of the aquaria. The flash group was exposed to photo-flashes. The control group was not exposed to these putative stressors but otherwise handled similarly. The mean \pm S.E. (a) activity before applying the stimuli and (b) the direct effect of applying the stimuli on the locomotor activity. *, $P<0 \cdot 05$.

d.f. $=2,42, P>0 \cdot 05$; interaction: d.f. $=4,84, P>0 \cdot 05$ ). Neither locomotor activity nor metabolism measurements showed significant changes from the start to the end of the experiment (ANOVA change over interval: $2 \mathrm{nd}+3 \mathrm{rd}$ day, 4 th +5 th day and 6 th +7 th day: d.f. $=2,84, P>0 \cdot 05)$.

In order to analyse the relationship between variation in daily metabolism and activity measurements, a regression analysis was carried out. This analysis showed that daytime routine metabolism was positively correlated with lowest night-time routine metabolism and locomotor activity (regression analysis: final model $r=0.70$; ANOVA: d.f. $=2,45, P<0.001$; lowest night-time metabolism: $P<0.001$; locomotor activity: $P<0 \cdot 01)$. 

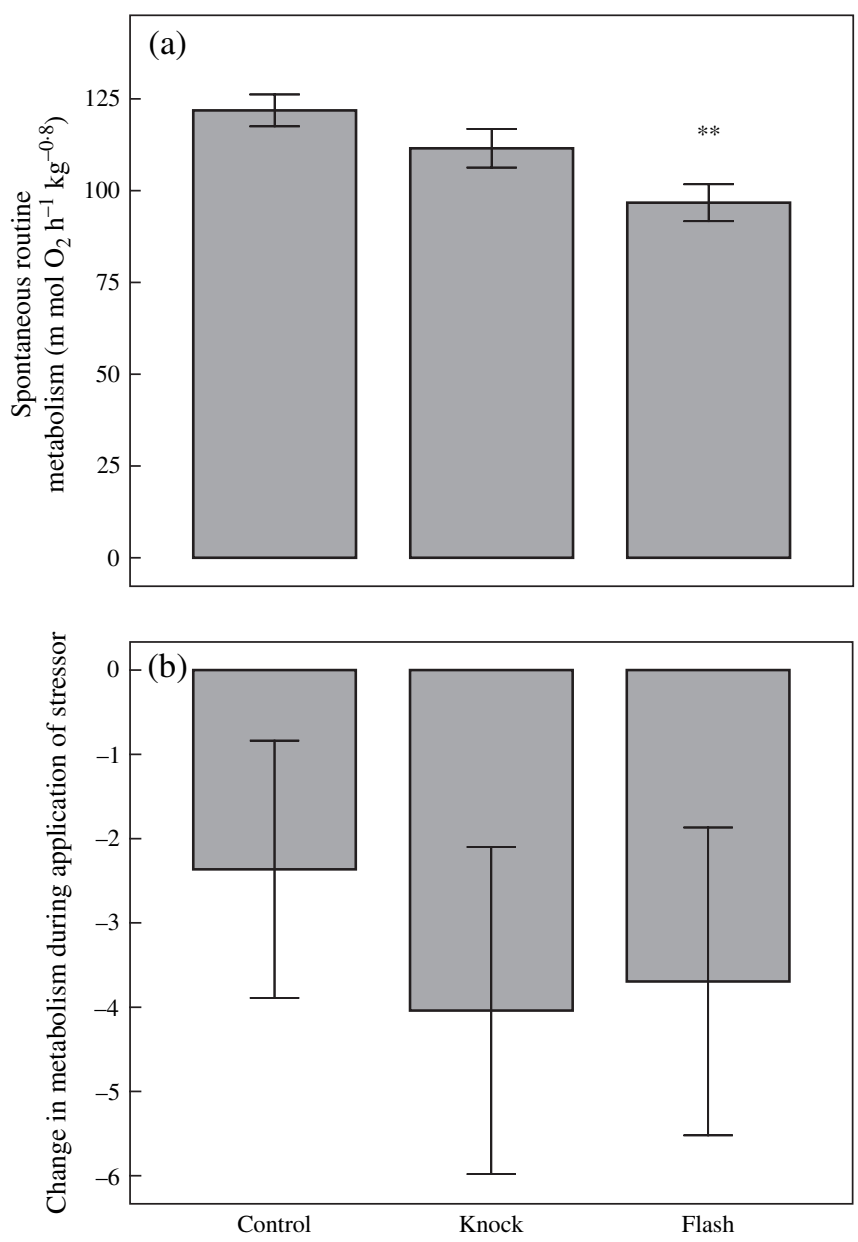

FIG. 2. The effect of 7 days of experimental treatment on Oreochromis mossambicus oxygen consumption. The knock group was exposed to repetitive knocks against the wall of the aquaria. The flash group was exposed to photo-flashes. The control group was not exposed to these stimuli but otherwise handled similarly. Mean \pm S.E. (a) metabolism before applying the stimuli and (b) the direct effect of applying the stimuli on metabolism. ${ }^{* *}, P<0 \cdot 01$.

\section{TREATMENT EFFECTS ON CORTISOL}

In accord with the results obtained for routine metabolism (Fig. 2), the analysis of cortisol showed a significant decrease in the 'flash' group, whereas no effect was detected in the 'knock' group (Fig. 4; ANOVA, d.f. $=2,40, P<$ $0 \cdot 001$; simple contrast: 'flash', $P=0.001$; 'knock', $P>0 \cdot 05$ ). Regression analysis did not detect a significant correlation between cortisol levels, activity and metabolic rate measurements, which might be due to the large variation in the measurements taken $\left(r_{\mathrm{s}}<0 \cdot 11, n=46, P>0 \cdot 05\right)$. 


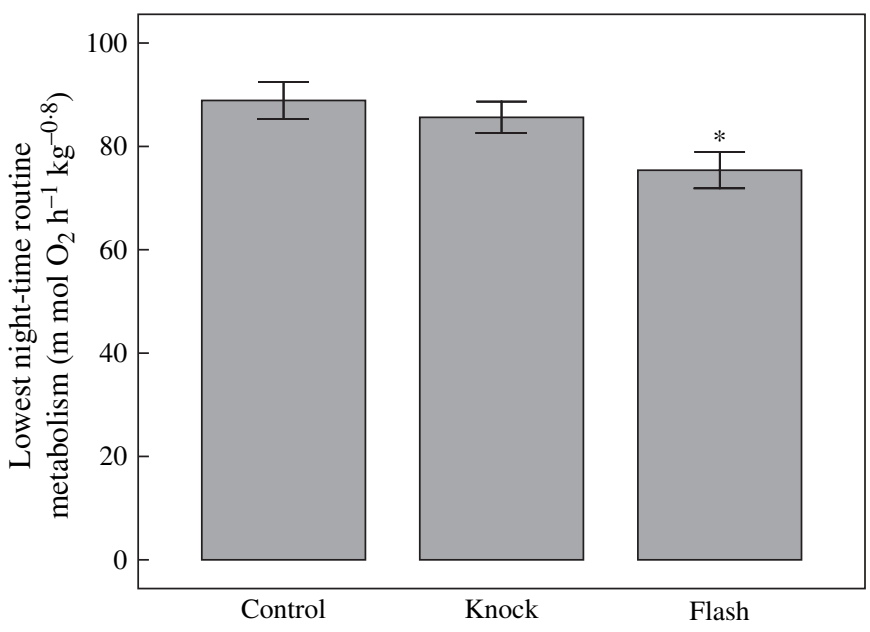

FIG. 3. The mean \pm S.E. effect of 7 days of experimental treatment on the lowest oxygen consumption of Oreochromis mossambicus measured during the dark period. The knock group was exposed to repetitive knocks against the wall of the aquaria. The flash group was exposed to photo-flashes. The control group was not exposed to these stimuli but otherwise handled similarly. ${ }^{*}, P<0 \cdot 05$.

\section{SEX-SPECIFIC STRESS RESPONSES}

Sex was added as an independent factor in all ANOVA. Sex showed neither any significant main effect (ANOVA, d.f. $=1,42, P>0.05$ ) nor any significant interaction effect (ANOVA, d.f. $=2,84, P>0.05$ ) with any of the measured variables (locomotor activity, oxygen consumption or cortisol).

\section{DISCUSSION}

The aim of this study was to analyse the consequences of common humaninduced stimuli for aquarium fishes. In line with expectations (Kratochvil \& Schwammer, 1997), males and females of $O$. mossambicus showed a temporary increase in locomotor activity in response to knocks on the wall of their aquarium. These knocks, however, did not have lasting effects on locomotor activity nor did they influence energy metabolism and cortisol levels. On the other hand, photo-flashes did not result in an immediate change in activity levels or metabolism but resulted in a general decrease in routine metabolic rates and cortisol levels.

Teleost species differ strongly in their sensitivity to acoustic stimuli (Smith et al., 2004b) and acoustic stimuli, as in day-active $v$. night-active species. This might greatly influence how different species respond to different types of stressors. Oreochromis mossambicus emit low-pitch sounds mainly during courtship activities (Amorim et al., 2003). For this species, the low-frequency knocks might thus comprise a more familiar stimulation than the light flashes. This might explain why longer lasting effects were measured as a consequence of flash light stimulation but not of knock stimulation in the experiment. Many species, called hearing specialists, however, are more sensitive to sounds (Smith 


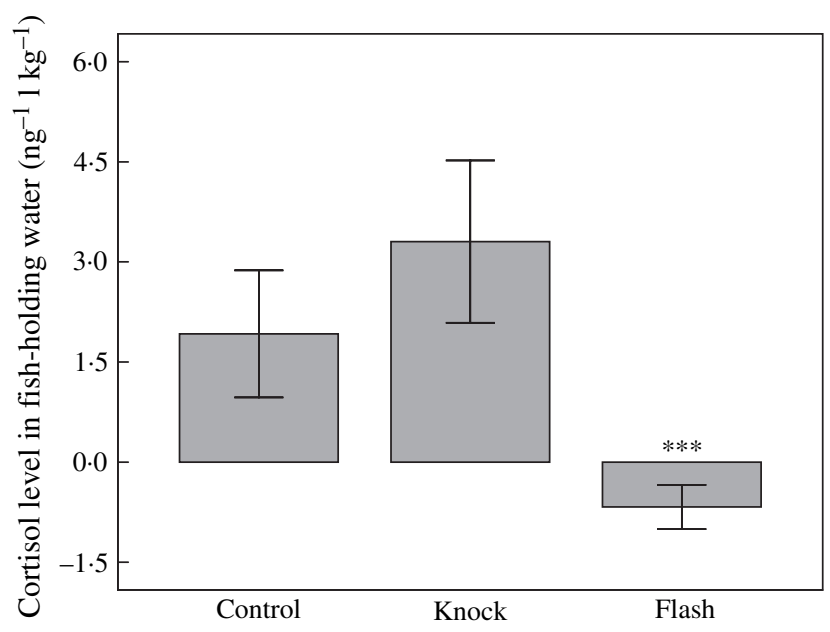

FIG. 4. The effect of 7 days of experimental treatment of Oreochromis mossambicus on cortisol levels measured at the end of the experiment from fish-holding water and corrected for the mass of the fish. The knock group was exposed to repetitive knocks against the wall of the aquaria. The flash group was exposed to photo-flashes. The control group was not exposed to these stimuli but otherwise handled similarly. ***, $P<0.001$.

et al., 2004a, b) and these species might have shown stronger responses to the knock treatment. The effects of these stimuli should thus be tested in a wider range of species to evaluate the effects of human-induced stimuli on aquarium species.

Knocks resulted in a peak in locomotor activity (c. $70 \%$ increase). Although locomotor activity was positively correlated with routine levels of metabolism, the substantial changes in locomotor activity during the exposure to the stimuli did not correlate with changes in oxygen consumption that were relatively small (on average $5.4 \%$ in the knock group). In a previous experiment on O. mossambicus, it was shown that the high-intensity movements made during escalated aggressive interactions are energetically costly to carry out (Ros et al., 2006). Comparable to the current study, however, van Ginneken et al. (1997) did not find significant effects of changes in 'non-social' swimming movements on oxygen consumption. Thus, changes in non-social routine swimming movements may have only marginal effects on oxygen consumption.

Cortisol levels were measured at the end of the experiment without application of any of the treatments (flash or knock). Thus, the decreased cortisol levels in fish exposed to photo-flashes suggest that this human-induced stimulus in this species may down-regulate cortisol secretion in a chronic manner. At a between-group comparison level, cortisol appeared to be modulated the same way as metabolic rates and locomotor activity. In O. mossambicus, cortisol treatment has been shown to increase glucose levels and to enhance amino acid mobilization, both important for high levels of locomotor activity (Vijayan et al., 1997). Therefore, the results are in accord with the suggestion that cortisol is important for the long-term regulation of metabolism in fishes (Vijayan et al., 1997). Contrary to what was described in other experiments in which 
fishes were exposed to different stressors (Barton, 2002), cortisol levels decreased rather than increased as a consequence of the flash treatment.

In light of the expected detrimental effect of chronic high glucocorticoid levels, it might be argued that the results obtained from repeated photo-flashes might hint at a beneficial calming effect. In fact, low levels of cortisol have been associated with social dominance in a related species, Haplochromis burtoni (Günther), (Fox et al., 1997). It should be taken into consideration, however, that the experimental fish were tested in an unnatural situation (isolation) and it might be that this had an effect on how the fish responded to the stimulation. Little is known about this, i.e. the effect of unnatural situations on the response to different stressors in fishes. For example, different species might respond differently to similar stressors, fishes might respond differently to stressors in isolation or in groups and fishes might respond differently depending on being confined or having space to escape the stressor (as in the 'desperado effect'; Grafen, 1987). Finally, both an increase and a decrease in cortisol might indicate an unbalance in homeostasis. Glucocorticoids have been shown to modulate physiological systems in a wide range of forms, for example, facilitating or inhibiting the expression of particular behaviours (Barton, 1997, 2002; Wingfield \& Sapolsky, 2003). It should be tested whether being exposed to photo-flashes affect the social behaviour of the fishes and whether this has consequences for important traits like growth, health and reproduction (Barton, 1997, 2002).

In conclusion, this study on $O$. mossambicus indicates that common humaninduced stimuli for aquarium held fishes might have opposite effects on activity, metabolic rate and cortisol levels. The direction of the effects of the stimuli on these variables and their time course should be considered when studying possible effects of these stimuli on the welfare of aquarium fishes. Finally, changes in these variables might be species dependent and the effect of stressors should thus be tested in a wide range of species.

T. Oliveira carried out the radioimmunoassays. I. M. da Silva and N. Pereira provided information about visitors to the Oceanario of Lisbon and helped during the study. L. Galhardo and colleagues of the UIE research unit of ISPA and two anonymous referees greatly helped improving the manuscript. The research of R.F.O. and A.F.H.R. is supported by the Pluriannual Programme of FCT (R\&D Unit 331/2001).

\section{References}

Amorim, M. C. P., Fonseca, P. J. \& Almada, V. C. (2003). Sound production during courtship and spawning of Oreochromis mossambicus: male-female and male-male interactions. Journal of Fish Biology 62, 658-672.

Arends, R. J. (1999). Adaptation to stress in fish: studies on sea bream (Sparus aurata L.) and carp (Cyprinus carpio). PhD Thesis, Katholieke Universtiteit Nijmegen, Nijmegen.

Arends, R. J., Mancera, J. M., Muñoz, J. L., Wendelaar Bonga, S. E. \& Flik, G. (1999). The stress response of the gilthead sea bream (Sparus aurata L.) to air exposure and confinement. Journal of Endocrinology 163, 149-157.

Barton, B. A. (1997). Stress in finfish: past, present and future - a historical perspective. In Fish Stress and Health in Aquaculture (Iwama, G. W., Sumpter, J., Pickering, A. D. \& Schreck, C. B., eds), pp. 1-33. Cambridge: Cambridge University Press. 
Barton, B. A. (2002). Stress in fishes: a diversity of responses with particular reference to changes in circulating corticosteroids. Integrative and Comparative Biology 42, 517-525.

Braithwaite, V. A. \& Huntingford, F. A. (2004). Fish and welfare: do fish have the capacity for pain perception and suffering? Animal Welfare 13, 87-92.

Bshary, R., Wickler, W. \& Fricke, H. (2002). Fish cognition: a primate's eye view. Animal Cognition 5, 1-13.

Cech, J. C. Jr. (1990). Respirometry. In Methods for Fish, Biology (Schreck, C. B. \& Moyle, P. B., eds), pp. 335-362. Bethesda, MD: American Fisheries Society.

Chandroo, K. P., Duncan, I. J. H. \& Moccia, R. D. (2004). Can fish suffer?: perspectives on sentience, pain, fear and stress. Applied Animal Behaviour Science 86, 225-250.

Clarke, A. \& Johnston, N. M. (1999). Scaling of metabolic rate with body mass and temperature in teleost fish. Journal of Animal Ecology 68, 893-905.

Cooke, S. J., Philipp, D. P., Schreer, J. F. \& McKinley, R. S. (2000). Locomotory impairment of nesting male largemouth bass following catch-and-release angling. North American Journal of Fisheries Management 20, 968-977.

Fox, H. E., White, S. A., Kao, M. H. \& Fernald, R. D. (1997). Stress and dominance in a social fish. The Journal of Neuroscience 17, 6463-6469.

van Ginneken, V. J. T., Addink, A. D. F. \& van den Thillart, G. E. E. J. M. (1996). Direct calorimetry of aquatic animals: effects of the combination of acidification and hypoxia on the metabolic rate of fish. Thermochimica Acta 276, 7-15.

van Ginneken, V. J. T., Addink, A. D. F., van den Thillart, G. E. E. J. M., Korner, F., Noldus, L. \& Buma, M. (1997). Metabolic rate and level of activity determined in tilapia (Oreochromis mossambicus Peters) by direct and indirect calorimetry and video monitoring. Thermochimica Acta 291, 1-13.

Grafen, A. (1987). The logic of divisively asymmetric contests: respect for ownership and the desperado effect. Animal Behaviour 35, 462-467.

Haddy, J. A. \& Pankhurst, N. W. (1999). Stress-induced changes in concentrations of plasma sex steroids in black bream. Journal of Fish Biology 55, 1304-1316.

Hirschenhauser, K., Ros, A. F. H., Carneiro, L. A., Oliveira, T., Silva, A., Canário, A. V. M. \& Oliveira, R. F. (2002). Non-invasive hormone assessment from fish-holding water. Advances in Ethology 37, 139.

Hirschenhauser, K., Taborsky, M., Oliveira, T., Canário, A. V. M. \& Oliveira, R. F. (2004). A test of the 'challenge hypothesis' in cichlid fish: simulated partner and territory intruder experiments. Animal Behaviour 68, 741-750.

Job, S. V. (1969). The respiratory metabolism of Tilapia mossambica. Marine Biology 2, 121-126.

Kratochvil, H. \& Schwammer, H. (1997). Reducing acoustic disturbances by aquarium visitors. Zoo Biology 16, 349-353.

Kutty, M. N. (1972). Respiratory quotient and ammonia excretion in Tilapia mossambica. Marine Biology 16, 126-133.

McEwen, B. S. (1998). Stress, adaptation, and disease. Allostasis and allostatic load. Annals of the New York Academy of Sciences 840, 33-44.

McEwen, B. S. \& Wingfield, J. C. (2003). The concept of allostasis in biology and biomedicine. Hormones and Behavior 43, 2-15.

Oidtmann, B. \& Hoffmann, R. W. (2001). Schmerzen und Leiden bei Fischen. Berliner und Münchener Tierärztliche Wochenschrift 114, 277-282.

Oliveira, R. F., Almada, V. C. \& Canário, A. V. (1996). Social modulation of sex steroid concentrations in the urine of male cichlid fish Oreochromis mossambicus. Hormones and Behavior 30, 2-12.

Oliveira, R. F., Carneiro, L. A. \& Canário, A. V. (2005). Behavioural endocrinology: no hormonal response in tied fights. Nature 437, 207-208.

Ros, A. F. H., Becker, K., Canário, A. V. M. \& Oliveira, R. F. (2004). Androgen levels and energy metabolism in Oreochromis mossambicus. Journal of Fish Biology 65, 895-905.

Ros, A. F. H., Becker, K. \& Oliveira, R. F. (2006). Aggressive behaviour and energy metabolism in a cichlid fish, Oreochromis mossambicus. Physiology and Behavior 89, 164-170. 
Scott, A. P. \& Sorensen, P. W. (1994). Time course of release of pheromonally active gonadal steroids and their conjugates by ovulatory goldfish. General and Comparative Endocrinology 96, 309-323.

Scott, A. P., Pinillos, M. \& Ellis, T. (2001). Why measure steroids in fish plasma when you can measure them in water? In Perspectives in Comparative Endocrinology: Unity and Diversity. Proceedings of the 14th International Congress of Comparative Endocrinology (Goos, H. J. Th., Rastogi, R. K., Vaudry, H. \& Pierantoni, R., eds), pp. 1291-1295. Bologna, Italy: Monduzzi Editore.

Selye, H. (1936). A syndrome produced by diverse nocuous agents. Nature 138, 32-35.

Smith, M. E., Kane, A. S. \& Popper, A. N. (2004a). Acoustical stress and hearing sensitivity in fishes: does the linear threshold shift hypothesis hold water? The Journal of Experimental Biology 207, 3591-3602.

Smith, M. E., Kane, A. S. \& Popper, A. N. (2004b). Noise-induced stress response and hearing loss in goldfish (Carassius auratus). Journal of Experimental Biology 207, 427-435.

Sneddon, L. U. (2002). Anatomical and electrophysiological analysis of the trigeminal nerve in a teleost fish, Oncorhynchus mykiss. Neuroscience Letters 319, 167-171.

Sneddon, L. U., Braithwaite, V. A. \& Gentle, M. J. (2003). Do fishes have nociceptors? Evidence for the evolution of a vertebrate sensory system. Proceedings of the Royal Society B 270, 1115-1121.

Sunny, F., Lakshmy, P. S. \& Oommen, O. V. (2002). Rapid action of cortisol and testosterone on lipogenic enzymes in a fresh water fish Oreochromis mossambicus: short-term in vivo and in vitro study. Comparative Biochemistry and Physiology B 131, 297-304.

Vijayan, M. M., Pereira, C., Grau, E. G. \& Iwama, G. K. (1997). Metabolic responses associated with confinement stress in tilapia: the role of cortisol. Comparative Biochemistry and Physiology C 116, 89-95.

Wingfield, J. C. \& Sapolsky, R. M. (2003). Reproduction and resistance to stress: when and how. Journal of Neuroendocrinology 15, 711-724.

Wysocki, L. E., Dittami, J. P. \& Ladich, F. (2006). Ship noise and cortisol secretion in European freshwater fishes. Biological Conservation 128, 501-508. 